\title{
REMEMORANDO AS IMAGENS DE FORMAÇÃO DE PROFESSORES: EM BUSCA DAS EXPERIÊNCIAS VIVIDAS
}

\author{
Cyntia Simioni França ${ }^{i}$ \\ Guilherme do Val Toledo Prado ${ }^{\text {ii }}$
}

\begin{abstract}
Resumo: $O$ artigo faz parte de uma investigação que teve como mote fundamental a relação entre formação docente e experiências vividas, fomentada por uma pesquisa-ação. $\mathrm{O}$ referencial teórico e metodológico dialoga com Walter Benjamin, Edward Palmer Thompson e Maria Carolina Bovério Galzerani, tendo em vista que partilhamos da ideia da formação docente como indissociável de experiências culturais, individuais e coletivas, políticas, sociais e econômicas, constituídas em processos ampliados de educação que atravessam as dimensões racionais e sensíveis dos professores. Dialogamos ainda, com as práticas de memória, considerando-as fecundas no movimento de resignificação da docência, mobilizadas por professores que resistem ao apagamento de suas histórias e de suas experiências vividas, no bojo de uma educação cada vez mais dominada por formações instrumentais.
\end{abstract}

Palavras-chave: Formação de Professores. Experiências. Rememoração.

\section{REMEMBERING THE IMAGES OF TEACHER TRAINING: IN SEARCH OF THE EXPERIENCES LIVED}

\begin{abstract}
The article is part of an investigation that had as fundamental theme the relationship between teacher education and experiences, fostered by an action research. The theoretical and methodological dialogue with Walter Benjamin, Edward Palmer Thompson and Maria Carolina Boverio Galzerani with a view that we share the idea of teacher education as inseparable from cultural, individual and collective, political, social and economic experiences , formed in extended processes education going through the rational dimensions and sensitive teacher. We dialogued also with the memory of practices, considering them fruitful in reframing movement of teachers, mobilized by teachers who resist the erasure of their stories and their experiences, in the midst of an education increasingly dominated by instrumental ensembles.
\end{abstract}

Key words: Teacher training. Experiences. Remembrance.

\section{Introdução}

Focalizamos neste artigo um recorte da pesquisa de doutorado que foi desenvolvida no contexto de um projeto de formação intitulado "O Canto da Odisseia e as Narrativas Docentes: 
dois mundos que dialogam na produção de conhecimento histórico educacional”, ligado ao Grupo de Estudos em Educação Continuada (GEPEC), da Faculdade de Educação da Unicamp.

Esta pesquisa/ação (ELLIOT, 1998; GERALDI, FIORENTINI E PEREIRA, 1998) se constituiu com a participação de professores da educação básica que aceitaram o convite de narrar coletivamente as suas experiências vividas. Os encontros com os professores aconteceram, nos períodos de setembro a dezembro de 2014, semanalmente, em uma escola estadual, na cidade de Londrina, no Estado do Paraná.

Durante os encontros com os professores, estabelecemos um diálogo com as preocupações do filósofo Walter Benjamin (1985) sobre as relações entre memória, experiência e narrativa na modernidade, em especial a partir do final do século XIX e no século XX. Refletindo sobre os textos "O Narrador" (1985) e "Experiência Pobreza” (1987), Benjamin nos alerta sobre o desaparecimento da experiência (Erfahrung) na modernidade concomitante ao declínio de narrar. Pode-se dizer que, com o avanço do capitalismo, esgarça-se a vida coletiva, o respeito às experiências dos anciãos, bem como a cadeia temporal. Passa a prevalecer a vivência, outro modo de vida que leva ao despojamento da imagem de si e do outro, a perda gradativa da memória quando o passado não é mais referência e os sujeitos são atropelados pelo tempo do relógio (THOMPSON, 1987).

Isso faz que o autor busque novos percursos no texto "O Narrador", como uma tentativa de pensar: de um lado, o declínio da experiência e das narrativas tradicionais, do outro lado, a possibilidade de encontrar e/ou (re)inventar narrativas diferentes das baseadas nas vivências (Erlebnis).

De forma concomitante a essas reflexões, ampliamos o debate, revisitando Edward Palmer Thompson, em sua obra Miséria da Teoria (1981), na qual o historiador explicita sua concepção de produção do conhecimento histórico. As ideias desse historiador são diferenciais para esta pesquisa, pois traz a experiência e a relação dialogal como o fundamento para a produção de conhecimento.

Escolhemos também, para dialogar a obra Odisseia, do autor Homero, datada do século VIII a.C., traduzida por Antônio Pinto de Carvalho, pois entendemos que se constitui como um importante documento histórico (THOMPSON, 1981) para a construção coletiva desse trabalho. Apostamos que essa obra literária seria um documento potencializador do processo de rememoração das experiências vividas dos professores. Tivemos como base a estratégia usada por Benjamin que procurou a literatura como um meio para produzir imagens 
significativas sobre os movimentos culturais dos séculos XIX e XX. Igualmente, acreditei que a Odisseia fosse uma produção capaz de engendrar sensibilidades e estimular as memórias dos professores.

Nesta pesquisa, buscamos uma tessitura de experiência singular, no mundo da escola e da universidade: a realização de uma pesquisa coletiva, mediante a rememoração das experiências vividas pelos professores para a produção de conhecimento histórico-educacional. Apostamos no trabalho colaborativo (de fazer pesquisa com os professores e não sobre os professores), ao mesmo tempo, em um trabalho autônomo e inventivo, com a potencialidade de promover a produção de conhecimento histórico-educacional, no qual o professor tem um papel de sujeito ativo.

Ao encontro das preocupações da historiadora Maria Carolina Bovério Galzerani durante o percurso investigativo, questionamos a produção dos conhecimentos predominantes nas práticas culturais na modernidade, as quais compreendem o saber escolar como inferior ao saber acadêmico, ou, ainda, como se este último ocupasse a posição de produtor de verdades absolutas. Além disso, indagamos as pesquisas realizadas com a temática de formação de professores, tendo em vista que muitas não os reconhecem como produtores de conhecimento histórico-educacional, bem como diluem as suas experiências e ainda trazem as informações sobre formações de professores com dados supostamente neutros e objetivos, com sugestões de propostas formativas utilitaristas e imediatistas, fundadas no tempo da urgência do capitalismo.

A partir do olhar inquieto, problematizamos, nessa pesquisa, a racionalidade instrumental/técnica (CONTRERAS, 1994), que busca aprisionar os professores em uma perspectiva de desvalorização do seu saber e, nesse sentido, não os considera como sujeitos da, e na, história. Ao contrário dessa visão, compartilhamos a imagem de professor não como mero transpositor didático (CHERVALLARD, 1995), mas sujeito produtor de conhecimento histórico-educacional (CHERVELL 1990; LOPES, 1992; 1997a; 1997b).

Assim, no projeto formativo "O Canto da Odisseia e Narrativas docentes: dois mundos que dialogam na produção de conhecimento histórico-educacional”, realizamos os encontros com os professores, focando as rememorações das experiências vividas.

Quanto a rememoração, essa pesquisa seguiu as pegadas do pensamento de Walter Benjamin. Para esse autor, o ato de rememorar se configura como imagens políticas, as quais implicam no questionamento das práticas culturais prevalecentes na modernidade consolidadas 
com o avanço do capitalismo e, concomitantemente, prenhe de potencialidades de invenção de novas práticas educacionais.

Em diálogo com Walter Benjamin, Maria Carolina Bovério Galzerani traz reflexões analíticas sobre a rememoração destacando que esse ato possibilita a recuperação de dimensões

\begin{abstract}
pessoais perdidas, ou no mínimo, ameaçadas face ao avanço do sistema capitalista. Dimensões psíquicas e sociais do ser humano que rememora. (...) afirmação de sua própria singularidade, sabendo-a constituída na relação, muitas vezes conflituosa, com "outras" pessoas. Ou ainda, permite o reconhecimento de que a (re) constituição temporal de sua vida só adquire sentido, na articulação com uma memória coletiva. Rememorar, além disso, para este filósofo significa sair da gaiola cultural que tende a nos aprisionar no sempre-igual e recuperarmos a dimensão do tempo, através da retomada da relação do presente, passado, futuro. (...) não significa Benjamin um devaneio ou uma evasão em direção a um passado, do qual o sujeito não quer mais emergir. (...) não se trata de não esquecer o passado, mas agir sobre o presente. $(2008$, p. 7$)$
\end{abstract}

Assim, rememorar para Walter Benjamin é um "ato político, com potencialidades de produzir um despertar dos sonhos, das fantasmagorias, para a construção de utopias" (GALZERANI, 2008, p. 21). Nesse sentido, a rememoração nessa investigação abarcou uma dimensão subjetiva, em busca do professor se enxergar mais inteiro, com potencialidades múltiplas, inventivas, criativas e singulares, dialogando com a concepção benjaminiana de rememoração que remete à constituição do sujeito. (GAGNEBIN, 1994;2014)

\title{
Imagens de formação de professores na modernidade
}

Logo que a estaca de oliveira, apesar de verde, começou a estar incandescente e a espalhar terrível clarão, tirei-a do fogo, peguei nela; os companheiros, de pé, me cercaram, porque um deus lhes incutira grande audácia. Eles tendo tomado à estaca de oliveira, apoiaram a ponta aguçada da mesma do globo ocular, enquanto eu, por cima, fazendo força, a fazia girar; assim como, quando se fura com o trato a trave de uma nau, se enrola uma das extremidades do instrumento uma correria, e esta é puxada dos dois lados para fazer rodar aquele no mesmo lugar, assim, nós segurando a estaca com a ponta em brasa, a fazíamos relutar no olho do Ciclope; o sangue corria em torno do ponto incandescente e entre as pálpebras e as sobrancelhas rechinava a pupila tostada, e as raízes se encarquilhavam, por ação da chama. (HOMERO, 1981, p.87) 
Trazemos o fragmento da narrativa da obra Odisseia para ser lida alegoricamente e problematizarmos a formação de professores. Quem é o Polifemo na modernidade capitalista? Como encontrar o tronco da oliveira nos processos formativos?

Temos como desafio encontrar o "tronco da oliveira" como Ulisses, para golpear o "Polifemo", no sentido de nos atentarmos para as tendências instrumentais (CONTRERAS, 2002) na modernidade que engessam, hierarquizam as relações e comprometem as propostas de formação de professores e nesta investigação buscamos propiciar um projeto formativo que fortalecesse a imagem do professor, enquanto sujeito ativo e intelectual. (GALZERANI, 2008a)

Somos movidos nessas discussões pelo pensamento do historiador Edward Palmer Thompson $(1981 ; 1987 ; 2002)$ e Walter Benjamin $(1985 ; 1986 ; 1987)$. Thompson tem inspirado muitos estudiosos do campo educacional a refletirem sobre formação ${ }^{\text {iii }}$, rompendo com os limites da formação vinculada estritamente aos espaços escolares/acadêmicos, mas compreende-as de forma alargada. Ao encontro do seu pensamento, problematizamos a acepção de experiências docentes concebidas no estrito limite da escola e da universidade (sem desconsiderá-las). Em movimento com as leituras de Thompson (1981) entendemos as experiências como o meio pelo qual nos tornarmos pessoas inteiras. Experiências como matéria de formação, uma formação historicamente situada no tempo e no espaço, produtora de culturas, na relação contraditória, ambivalente, com “outras” práticas culturais, localizadas também historicamente. Considerando que os sujeitos se constituem e são constituídos pelas experiências em diversas situações do cotidiano, desde os acontecimentos relacionados à família, ao lazer, ao trabalho, a igreja e muitas outras possibilidades humanas. (THOMPSON, 1981)

Assim, Thompson ampliou a nossa concepção de formação continuada de professores, no sentido de ajudar a nos distanciar dos impositivos da racionalidade instrumental, que entende a formação estritamente ligada à escola e a universidade, bem como aos aspectos da profissão. Portanto não limitamos, nessa viagem de pesquisa, a acepção de experiência àquela estritamente voltada ao campo docente, mas consideramos as experiências mais amplas dos professores, como formadoras, vinculadas a uma dimensão de longa duração (desde os primórdios de vida do professor), historicamente situadas e, por conseguinte, formadoras.

Embora existam tendências culturais dominantes na modernidade capitalista que trazem a concepção de formação docente restrita aos espaços acadêmicos, reconhecemos e dialogo com essas tendências dominantes, com as suas resistências, e com os conflitos imbricados nas 
práticas de formação docentes e buscamos (re)significá-los nesta pesquisa. Assumindo, a partir de Thompson (1981), que dominação/resistência não são como blocos monolíticos, pertencentes a polos opostos, mas que tanto a dominação como a resistência se entrecruzam, e só acontecem pelo fato de estarem imbricadas.

É nesse sentido que a formação de professores se insere em um terreno de lutas, de ambiguidades, de contradições, no qual as diferentes concepções estão disputando espaços simbólicos e se transformando.

Thompson contribui para refletirmos sobre a importância de considerar os professores como sujeitos que se constituem historicamente, em suas experiências vividas, as quais são atravessadas pelos movimentos de tensão/distensão e pelas fronteiras da resistência e conflitos no seu cotidiano.

Em seu livro a "Miséria da Teoria e um Planetário de Erros" (1981), o autor faz uma crítica obstinada aos estruturalistas que não apresentam as experiências humanas nas pesquisas. $\mathrm{O}$ autor explica que, o pesquisador, ao desconsiderar o papel ativo dos homens no curso da história, transforma-os em simples desdobramentos de estruturas. Pensando em romper com a ótica estruturalista para esta pesquisa, procuramos nos afastar das estruturas que impõem diferentes ações impositivas aos professores, desconsiderando-os enquanto sujeitos produtores de conhecimento histórico e não cair nas "armadilhas" da racionalidade instrumental (CONTRERAS,1992), elaborando prescrições aos professores durante o desenvolvimento do projeto formativo "O canto da Odisseia e as narrativas docentes: dois mundos que dialogam na produção de conhecimento histórico-educacional”.

Como profissionais da educação básica e da universidade, enxergamos, contemporaneamente, muitas tendências de práticas de formação continuada de professores que pretendem imperar, pautadas na racionalidade instrumental, oferecendo cursos utilitaristas e imediatistas aos professores, baseados no modelo "treinamento". Essa vertente implica em uma formação de tecnólogos que apenas executam, mas não conhecem os fundamentos do seu fazer, limitando a um saber prático e desvinculado do contexto social.

A partir da perspectiva crítica à racionalidade instrumental, é possível pensar, também, na importância do rompimento da visão do ofício dos professores como simples "treinadores" (qualquer pessoa bem treinada nas metodologias e nas didáticas de ensino exerceria o papel do professor). Os cursos de formação continuada como treinamento contribuem para reafirmar a profissão docente como um fazer "desprofissionalizado" e os professores, transmissores de 
informações, ou seja, meros reprodutores de técnicas ou habilidades de determinada disciplina (ARROYO, 2002).

A lógica da formação instrumental centra-se em um sistema assegurando a adaptação técnica e, eventualmente, a psicológica dos professores ao novo contexto; produção de qualificações novas ou substituição das que se mostram obsoletas (CANÁRIO, 2003).

Além disso, há uma perda da legibilidade do trabalho docente, no sentido de, muitas vezes, os professores não compreenderem o que estão fazendo no cotidiano escolar. Em diálogo com Villa (1998), compreendemos que a perda do controle do professor sobre o processo de trabalho contribui para a desqualificação do professor, principalmente, porque aqueles que constroem os currículos baseados por competências são apenas especialistas (administradores de alto padrão), e os que executam são os professores. Esta é uma visão mercadológica da escola, "na qual o ensino passa a ser visto apenas como uma parte de uma linha de produção" (VILLA, 1998, p. 52).

A formação continuada baseada no modelo de competência impacta diretamente na identidade do professor: segundo Harvey (1989, p. 258), este modelo é sustentado na dinâmica do descarte (das ideias, dos valores, dos relacionamentos estáveis, do apego às coisas e pessoas). Assim, as coisas, dentre o trabalho docente e a formação dos professores, modificam-se e tornam-se na maioria das vezes, descartáveis.

Para Harvey (1989), a reestruturação do capital na modernidade "golpeou a experiência cotidiana do indivíduo", bem como devastou as tradições, as identidades. A modernidade alterou as sensibilidades dos sujeitos, o fazer humano e hierarquizou os conhecimentos, tanto na escola como na universidade (GALZERANI, 2008).

A fragmentação e a flexibilização do tempo, a supervalorização da competência, o deslocamento do processo de trabalho para os resultados do trabalho, impossibilitam, muitas vezes, que os professores narrem suas experiências (SENNETT, 1988; 2001; 2012). Assim, as identidades vão sendo esquecidas, apagadas e os sujeitos tornando-se iguais, ou como nos dizeres de Benjamin (2006), tudo se transforma em "fantasmagorias", inclusive os professores, vistos como mercadoria, porém, ao mesmo tempo, os sujeitos podem se renovar, resistir e criar outras “táticas” (CERTEAU, 2012) de sobrevivência em suas práticas culturais.

Mergulhamos na obra Costumes em Comum: estudos sobre a cultura popular tradicional, de Thompson (1998), flagramos uma contribuição do autor, ao pensar na possibilidade de instaurar "outras" possibilidades de viver na modernidade, apesar das 
condições sociais, políticas e econômicas. Ao estudar os trabalhadores de uma fábrica na Inglaterra, no século XVIII, e as transformações sócio-econômico-político-culturais do período industrial, o autor compreende que tais mudanças vão sendo incorporadas no cotidiano dos operários. Porém, é perceptível que costumes novos não sobrepõem aos costumes "antigos". Pelo contrário, eles se imbricam em uma relação tensa, marcada ora pela dominação e/ou ora resistência. Os sujeitos selecionam as tendências culturais dominantes em suas experiências e incorporam elementos, bem como as negam, adequando às suas necessidades.

Tanto Thompson (1988), como Benjamin, entendem que as experiências são construídas e podem ser modificadas na relação com outras práticas culturais. Thompson, acredita ser possível resistir à dominação, mesmo por meio da incorporação dos elementos culturais dominantes, mas reinventando práticas "outras", a partir dos interesses daqueles que apresentam as resistências. Como se trata de um campo tensionado, de disputas de forças, de representações, dominações e resistências são maneiras de lutas (re)inventadas constantemente, movimentando o processo histórico. Sendo assim, o campo cultural é plural, reinventado constantemente no cotidiano (PAIM, 2005).

Assim, entendemos que, por meio das experiências, os professores são reinseridos na história, abrindo um campo de potencialidades, no âmbito do seu trabalho. Além disso, Thompson (1981, p. 182) traz grandes contribuições no campo da educação, sobretudo, nos seus estudos sobre as relações entre a experiência com as noções de cultura, pois compreende que os "homens e mulheres experimentam sua experiência como sentimento e lidam com esses sentimentos na cultura, como normas, obrigações familiares e de parentesco, e reciprocidades".

Nesse sentido, levar em conta as experiências vividas dos professores é a base para pensar a formação continuada pelo viés da racionalidade estética. (MATOS, 1989)

\section{Algumas impressões da viagem de pesquisa}

Considerando tais reflexões, o projeto "O Canto da Odisseia e as narrativas docentes dois mundos que dialogam na produção de conhecimento histórico-educacional" mergulhou nas experiências vividas dos professores para produzir conhecimentos histórico-educacionais em uma relação mais dialogal e coletiva. Além disso, buscou construir "outra" possibilidade de formação, pautando-se em um projeto emancipatório para cada sujeito que participou do processo, nesse casso tanto para os pesquisadores como para os professores. 
Pautamos nas ferramentas teórico-metodológicas de Benjamin e Thompson, buscando questionar os modelos teóricos da modernidade que procuram interditar a partilha das experiências dos professores. Seguimos "outros" caminhos para deixar aflorar as sensibilidades $^{\text {iv }}$, enveredando pelas lentes da racionalidade estética (MATOS, 1989).

Racionalidade que possibilitou aos professores se reconhecerem em suas realidades, na relação com o outro, nas suas (in)completudes e na sua inteireza, nos momentos de rememorações coletivas e individuais durante os encontros realizados.

Quando nos propusemos a promover o diálogo com os professores na pesquisa, partimos na contramão dos elementos da modernidade e buscamos fortalecer a imagem de professores como sujeitos de suas trajetórias, capazes de produzir conhecimentos históricos, amalgamando diferente saberes, relativos ao passado e ao presente, na relação com os desafios vividos nos dias atuais (GALZERANI, 2013). Procuramos recuperar outros saberes dos professores, os saberes experienciais, no sentido larrousiano (2003). Saberes pessoais, subjetivos, relativos. Saberes receptivos, atravessados pela abertura ao outro, em movimento e transformação. Saberes imbricados em uma trajetória dilatada de formação docente que abarca a longa duração (TARDIFF, 2014).

Caminhamos coletivamente pelas lentes da racionalidade estética que entende a formação como uma possibilidade do professor alargar a sua visão de mundo. Uma formação que abarca as experiências vividas, articuladas as práticas socioculturais mais amplas. Formação $^{v}$ que se permite transformar pelo conhecimento, na relação com o outro, em múltiplos espaços e tempos.

Neste sentido, procuramos colocar em ação neste projeto uma concepção de formação docente como processo inacabado, onde o outro nos constitui e que tem como fundamento

la diversidade cognitiva de los saberes, la pluralidade de sus vínculos historicamente dados, así como también el diálogo que esta diversidade y pluralidade posibilitan. Diálogo concebido como actitud comunicacional, em términos de Habermas (1987) como confrontación de lógias, no pautado por la racionalidad instrumental. Diálogo cuestionador de las relaciones de saber/poder presentes em los contextos de trabajo educacional, capaz de desconstruir lo juegos (tanto el oficial como el oficioso) de producción de sentidos. Diálogo aberto a la exploración histórica de sí mesmo, em la relación com los otros, situados, inclusos em otros tempos y lugares. (GALZERANI, 2008, p.18) 
Nesse sentido, o projeto pesquisa-ação preocupou-se em adentrar nas brechas da "barbárie" instalada na modernidade e construir um projeto de formação continuada que, sobretudo, considere a dimensão humana dos professores. Formação que focou a rememoração das experiências vividas. A volta ao passado ${ }^{\text {vi }}$ não foi apenas para conhecê-lo tal como foi, mas para agir no presente (GALZERANI, 2008).

Com esse projeto formativo, pudemos perceber que apesar das contradições da modernidade, sabemos que nunca houve um "monumento de cultura que não fosse um monumento de barbárie", possibilitando olhar o monumento do lado do avesso e estabelecer uma relação "outra”. (BENJAMIN, 1987a, p. 225)

Cabe destacar que o projeto de pesquisa-ação caminhou em direção contrária à "barbárie”, buscando as experiências dos professores que estão sendo minadas pelo avanço da modernidade, estimulando os professores a compreenderem que tudo pode ser diferente do que um dia aconteceu no passado sendo, portanto, possível mudar o tempo vazio de sentido, mecânico, cristalizado e unidimensional no presente. Portanto, a pesquisa não se restringe ao debate sobre formação continuada, mas ao "despertar", no sentido benjaminiano, de que podemos trazer "outras" imagens (sentidos e relações) de formação docente na modernidade.

Nesse sentido questionamos: podemos nos utilizar da "tática" do vinho, quando nos depararmos em "situações conflituais" em processos formativos, como na passagem alegórica de Ulisses com o Polifemo? Ou construir o elemento surpresa, indo à caça e usando a astúcia para sair do inextricável, daquilo que nos enclausura e suspende nossa liberdade como aquelas prescrições que encontramos em grande parte dos cursos de formação de professores? Porém, como e quando usar da "tática" e da "astúcia" de Ulisses nos processos formativos? Quando podemos encontrar o momento para executar o golpe no "ciclope"? (CERTEAU, 2012).

No que diz respeito à tática, às astúcias e estratégias, articulei as ferramentas teóricometodológicas do Michel De Certeau (2012, p. 94-95), de seu livro A Invenção do Cotidiano, que orienta beneficiarmo-nos do momento da "mobilidade, mas nunca da docilidade aos azares do tempo, para captar no voo as possibilidades oferecidas por um instante". Segundo o autor, é importante utilizar "as falhas que as conjunturas particulares vão abrindo na vigilância do poder proprietário". Estabeleço essa relação com a pesquisa, no que tange ao debate de formação continuada de professores, que estabelece regras, modelos de como devem ser os processos de construção de conhecimento nos cursos de formação continuada. Será que não é a hora de 
aprender com a astúcia de Ulisses, não correndo o risco de "entregar-se à classe dominante, como seu instrumento?” (BENJAMIN, 1985, p. 224).

Até que ponto é necessário um tipo de astúcia para nos livrarmos das armadilhas que estão marcadas em nossos corpos e em nossas atitudes, decorrentes de nossa formação? A fim de desarmar o pensamento do "sempre igual", é preciso um saber astuto para flagrar os perigos que ameaçam a existência humana de mil e uma maneiras, pelo "inimigo que não tem cessado de vencer" (BENJAMIN, 1985, p. 225).

Como Ulisses libertou-se das artimanhas do Polifemo, também, nesta pesquisa, procurei, junto com os professores, "táticas" para golpear a racionalidade instrumental que busca impor uma visão de professor fragmentado, desconsiderando as suas experiências docentes, compartimentalizando e hierarquizando seus saberes. Táticas estas que rompem ${ }^{\text {vii }}$ com as "barreiras de competência entre as duas forças produtivas - a material e a intelectual" (BENJAMIN, 1994, p. 129).

A derrota a priori de Ulisses diante do Polifemo não levou o herói a desistir de encontrar brechas para modificar a sua condição. Podemos nos inspirar na sua história e encontrar também um tronco de oliveira para nos servir, como fez Ulisses nesse episódio (cortou cuidadosamente, descascou-o, aguçou uma das suas extremidades e endureceu no fogo ardente, e aguardou o momento oportuno para se libertar do gigante).

Se a modernidade anuncia o esfacelamento da vida e as formatações dos cursos de formação continuada, cabe a nós aceitarmos o convite de Benjamin de "escovar a história a contrapelo", encontrando o "tronco da oliveira" para golpear as tendências racionalistas instrumentais e seguir os caminhos da racionalidade estética, ampliando a dimensão "sensível dos conhecimentos, bem como das relações entre os diferentes saberes. Racionalidade capaz de reencantar as práticas de produção de saberes, muitas vezes, instrumentalizadas e hierarquizadas, as quais acabam por despoetizar as relações educativas, excluindo sujeitos e saberes" (GALZERANI, 2008b, p. 1). Enfim, racionalidade estética que enxerga o sujeito tanto sob o ponto de vista social como psicológico, portador de sensibilidades e como seres (in) completos.

Ao encontro dessas reflexões, buscamos viver com os professores uma experiência estética de formação continuada, aberta ao diálogo, à partilha de experiências e em busca de relações mais humanizadoras. 


\section{Referências}

ARROYO, Miguel G. Ofício de mestre: imagens e auto-imagens. 5. ed. Petrópolis: Vozes, 2002.

BENJAMIN, Walter. "O narrador”, in Obras Escolhidas, V. I, Magia e técnica, arte e política, trad. S.P. ROUANET, São Paulo: Brasiliense, 1985. $232,1985$.

Sobre o conceito de história. In Obras Escolhidas I. São Paulo: Brasiliense, p.222-

Infância em Berlim por volta de 1900. In Obras Escolhidas II. Rua de mão única. São Paulo: Editora Brasiliense, p. 71-142, 1987.

. "Experiência e Pobreza”, in Obras Escolhidas, V. I, Magia e técnica, arte e política, trad. S.P. ROUANET, São Paulo: Brasiliense, 1985.

. "Imagens do pensamento", in Obras Escolhidas, V. II, Magia e técnica, arte e política, trad. S.P. ROUANET, São Paulo: Brasiliense, 1987.

Paulo, 1986.

Passagens. Belo Horizonte: Ed. da UFMG/Imprensa Nacional do estado de São

CERTEAU, Michel De. A invenção do cotidiano. Petrópolis: Vozes, 2012.

CHEVALLARD, Yves. La transposición didáctica. Del saber sábio al saber enseñado.

Buenos Aires: Ainque Grupo Editor, 1995.

CHERVEL, A. História das disciplinas escolares: reflexões sobre um campo de pesquisa, in Teoria e Educação, n.2, Porto Alegre:Pannônica, 1990, pp.177-229.

CONTRERAS, José. A autonomia de professores. São Paulo: Cortez, 2002.

ELLIOT, J. Recolocando a pesquisa-ação em seu lugar original e próprio. In: GERALDI, C. M. G.; FIORENTINI, D.; PEREIRA, E. M. A. (Orgs.). Cartografias do trabalho docente. Campinas: Mercado da Letras, 1998, p. 137-152.

GAGNEBIN, Jeanne Marie. História e narração em Walter Benjamin. São Paulo:

Perspectiva: FAPESP: Campinas: SP: Editora da Universidade Estadual de Campinas, 1994.

34, 2014.

Limiar, aura e rememoração: ensaios sobre Walter Benjamin. São Paulo: Editora

GALZERANI, Maria Carolina Bovério; PARDO, Maria Benedita Lima; LOPES, Amélia (org). Uma "nueva" cultura para la formación de maestros: es posible? Porto, Portugal: Ed. Livipsic/AMSE-AMCE-WAER, 2008a. 
GALZERANI, Maria Carolina Bovério. Pesquisa em Ensino de História: Saberes e Poderes na Contemporaneidade. In. SILVA, Marcos (org). Campinas, SP: Papirus, 2013.

. Memória, história e (re) invenção educacional: uma tessitura coletiva na escola pública. In: MENEZES, Maria Cristina (Org.). Educação, memória, história: possibilidades, leituras. Campinas: Mercado das Letras, 2004.

Imagens entrecruzadas de infância e de produção de conhecimento histórico em Walter Benjamin. In Goulart de Faria, Ana Lúcia; Fabri, Zeila de Brito; Prado, Patrícia Dias (org.) Por uma cultura da infância. Metodologias de pesquisa com crianças. Campinas, SP: Autores Associados, p.48-68, 2002.

. Memória, tempo e História: perspectivas teórico-metodológicas para a pesquisa em ensino de história. In Cadernos CEOM, n.28, Chapecó, SC: Unochapecó, 2008b.

GAY, Peter. A experiência burguesa. Da Rainha Vitória a Freud: a educação dos sentidos. São Paulo: Companhia das Letras, 1988.

HARVEY, David. A condição pós-moderna - uma pesquisa sobre as origens da mudança social. São Paulo: Edições Loyola, 1989.

HOMERO. Odisseia. Tradução de Antônio Pinto de Carvalho. São Paulo: Abril Cultural, 1981.

KRAMER, Sonia (Orgs.); JOBIM E SOUZA, Solange; Política, cidade, educação: itinerários de Walter Benjamin. Rio de Janeiro: Contraponto. Ed. PUC-Rio, 2009.

LOPES, Alice Ribeiro Casimiro. Conhecimento escolar: processos de seleção cultural e mediação didática. Educação e realidade, Porto Alegre, v. 22, n. 1, p. 95-112, jan./jun. 1997a.

MATOS, Olgária. Os arcanos do inteiramente outro. São Pulo: Brasiliense. 1989.

PAIM, Elison Antônio. Memórias e experiências do fazer-se professor. Tese de Doutorado. Campinas: FE/UNICAMP, 2005.

SENNETT, Richard. O declínio do homem público. São Paulo: Cia das Letras, 1988. . A corrosão do caráter - consequências pessoais do trabalho no novo capitalismo. 5. ed. São Paulo: Record, 2001. . O Artífice. Rio de Janeiro: Record, 2012.

SOLIGO, R.; PRADO, G. V. T. Quem forma quem afinal? In: VICENTINI, A. A. F.; FARIAS, M. N. O.; SADALLA, A. M. F. A.; PRADO, G. V. T. (Orgs.), Professor formador: histórias contadas e cotidianos vividos. Campinas, SP 
TARDIFF, Maurice. Saberes docentes e formação profissional. Petrópolis: Editora Vozes, 2014.

THOMPSON, Edward Palmer. A miséria da teoria ou um planetário de erros. Rio de JaneiroRJ: Zahar, 1981.

. A Formação da Classe Operária Inglesa. Rio de Janeiro: Paz e Terra, 1987.

. Os Românticos: a Inglaterra na era revolucionária. Rio de Janeiro: Civilização

Brasileira, 2002.

Costumes em Comum: Tudo sobre a Cultura Popular Tradicional. São Paulo:

Companhia das Letras, 1998.

\footnotetext{
${ }^{\text {i }}$ Doutora em Educação pela Unicamp. Membro do grupo de pesquisa GEPEC e Kairós. Docente da UNOPAR (Universidade do Norte do Paraná). Professora da rede estadual de ensino, no estado do Paraná.

ii Departamento de Ensino e Práticas Culturais da Faculdade de Educação da UNICAMP e Coordenador do GEPEC/FE/UNICAMP.

iii Compartilhamos da concepção de Elison Paim que para além de formar professores há um fazer-se professor, em que há um emaranhado de relações que se constituem quando os professores se relacionam com diferentes sujeitos e os constituem, ao mesmo tempo. Para aprofundar a discussão pertinente a formação de professores, a referência para esse debate é a tese de doutorado: PAIM, Elison. Memórias e experiências do fazer-se professor. Tese de Doutorado. Universidade Estadual de Campinas. Campinas, São Paulo, 2005.

${ }^{i v}$ A obra Coração Desvelado, do autor Peter Gay (1988), também contribuiu a pensar a racionalidade estética como uma possibilidade de abarcar uma noção ampliada de sujeito, dotado de racionalidades e sensibilidades, de emoções, expectativas, desejos, frustrações presentes nas memórias autobiográficas e nas correspondências íntimas de suas produções do século XX. O autor procura compreender o fascínio experimentado pelos sujeitos em relação à vida em todos os seus aspectos.

${ }^{\mathrm{V}} \mathrm{O}$ artigo dos autores SOLIGO, R.; PRADO, G. V. T. Quem forma quem afinal? In: VICENTINI, A. A. F.; FARIAS, M. N. O.; SADALLA, A. M. F. A.; PRADO, G. V. T. (Orgs.), Professor formador: histórias contadas e cotidianos vividos. Campinas, SP: Mercado das Letras, 2008, complementa o debate acerca da formação de professores.

viPensar a formação continuada de professores sobre o nosso tempo exige um repensar das políticas públicas impositivas que desconsideram o pensar e o fazer dos docentes, e transmite o "passado para preparar um suposto futuro, mas deixa o presente intocado, sem mudanças, muitas vezes sem sentido" (KRAMER, 2009, p. 299).

vii "Somente a superação daquelas esferas compartimentalizadas de competência no processo de produção intelectual, que a concepção burguesa considera fundamentais, transforma essa produção em algo politicamente válido; além disso, as barreiras de competência entre as duas forças produtivas — a material e a intelectual —, erigidas para separá-las, precisam ser derrubadas conjuntamente” (BENJAMIN, 1985, p.129).
} 